\title{
EDITORIAL
}

\section{Ecology, Economy and Society through an Interdisciplinary Lens}

\author{
Kuntala Lahiri-Dutt *
}

The idea of interdisciplinarity is to create new knowledge by drawing from across disciplinary boundaries. Interdisciplinarity has become the buzzword of the day; academic researchers appreciate interdisciplinarity and aim to pursue it in research-related activities. In 2015, Nature devoted a full issue discussing how to approach the 'grand challenges' that are facing human societies today, challenges involving energy, water, climate, food and human health. Understanding complex topics such as nature (or climate change) requires us to go beyond discipline-based methods to develop systematic analyses that can bring together the explanations and interpretations of both the social and natural worlds.

Disciplines themselves are time- or space-specific constructions, and orderings of knowledge and epistemology, offering just one temporally- and culturally-grounded explanation of the world. Interdisciplinarity brings to the fore the emergent properties of complex systems and the need for methodological pluralism to understand that nature and the socio-natural contexts in the world that are determined not just by one factor. Scholars argue that interdisciplinary research efforts to integrate the social and natural sciences have given rise to questions such as whether a knowledge practice is too disciplinary, or interdisciplinary, or not disciplinary enough. Indeed, each discipline understands and values interdisciplinarity differently, and these values differ remarkably across the sciences.

\footnotetext{
* Coordinating Editor (2019-20). Crawford School of Public Policy, ANU College of Asia and the Pacific, The Australian National University, Room 3.25, JG Crawford Building, Lennox Crossing, ACTON, ACT 2601, Australia; kuntala.lahiri-dutt@anu.edu.au

Copyright (C) Lahiri-Dutt 2020. Released under Creative Commons AttributionNonCommercial 4.0 International licence (CC BY-NC 4.0) by the author.

Published by Indian Society for Ecological Economics (INSEE), c/o Institute of Economic Growth, University Enclave, North Campus, Delhi 110007.
}

ISSN: 2581-6152 (print); 2581-6101 (web).

DOI: https://doi.org/10.37773/ees.v3i1.84 
Interdisciplinarity obscures as much as it illuminates the diverse practices under its rubric, making it extremely difficult to forge ties between disciplines or discipline-based methods. In reality, disciplines have continued to remain 'discrete entities', presenting their distinct disciplinary perspectives, usage of methods, and bodies of knowledge. The organisation of higher education is partly responsible for this. Dissemination of research outputs to selective audiences through discipline-focused journal venues is also to blame. In considering our understanding of pressing ecological challenges, a conflicting and confused picture emerges; beyond the academe, disciplinary entities are becoming more fluid. Yet, at the same time, researchers have increasingly discussed the various possible definitions and categories of interdisciplinarity; debating the differences between multi-, cross-, inter-, pluri-, trans-, meta-,and other forms of hybridities in research methodologies. The complexities and difficulties of moving from 'multidisciplinarity' to genuine 'interdisciplinarity' as well as the alternative trajectory of 'transdisciplinarity' continue to elude most researchers.

The need, therefore, is to 'think outside the box', and creatively, in our undertaking of making research on nature and human society interdisciplinary. Creative interdisciplinarity involves establishing mechanisms and instances through which individual disciplinary knowledges can be appropriately translated in order to be articulated in interdisciplinary scholarly research that can also effectively converse with heterogeneous policy communities. This issue of Ecology, Economy and Society offers glimpses into interdisciplinary research on a broad swathe of topics. The contributions also show how working across disciplinary perspectives appears in reality, and what conversations we could now have to reflect on where these theoretical and empirically based activities are taking us.

The 'Commentary' by Marina Fischer-Kowalski on how one of the leading religious figures is responding to the global problem of climate change and ecological destruction is an example at hand. It resonates with the observation in EES (Bawa EES 2 (2), 2) that as academics and researchers we are an integral part of the society, and we must work together in order to meet the goal of sustainability.

The thematic essays/research papers published in this issue reflect the ongoing conversations between scholars from different disciplines. In his article, Chandan Singha treats the question through a study of soil, one of the finest-grained elements of nature which sustains almost all life in the earth. The study reviews the success and failure of three kinds of action, individual, collective and government, in different parts of the world, and shows that not all the collective action by development/civil society 
agencies and the government have been successful in ensuring successful management of the soil quality of a watershed. The research paper by Dasgupta, Guha and Wheeler uses regression analysis of survey data from the Indian part of the Sundarbans to examine variations in environmental risk assessments across socioeconomic classes and localities. It shows that locally-oriented collective action, along with local governance that promotes non-elite participation, might make collective action easier when elite and non-elite households have similar assessments of environmental risks.

The notes from the field also reflect interdisciplinarity. Thakur and others take us to the Himalayan state of Sikkim, where, in the rain-shadow areas, freshwater is available only from natural sources. They show that more women are concerned about the loss of water availability than men, for in most local households, the responsibility of water-collection remains gendered. Abraham and Neetha show how differing perceptions of ponds and wells make a difference. The perception that 'wells are like water ATMs while ponds are equivalent to saving banks', had led to a resistance to the construction of farm ponds due to the belief that 'precious land would be lost' without receiving commensurate gains from improved farm outputs. However, once the resistance lessened, farm ponds yielded tangible benefits even for low-income households practising subsistence agriculture.

The 'Conversations' section in this issue is about mining in India. Largescale extractive resource developments are at the heart of controversies related to the well-being of the planet, human society, and indeed the sustainability of the way economic development has been conceived. Most national governments find extractive developments as the quick and easy way to earn revenues to improve fiscal health, and justify these developments on economic grounds. India is no exception. These economic opportunities, however, come with significant environmental challenges. There are important challenges regarding local communities' rights as large-scale resource developments rarely, if ever, benefit indigenous people and local communities who suffer from the negative impacts of mining on their cultures, economies and social fabrics. There is no wonder why, in recent decades, indigenous groups and their allies have battled to change this situation, sometimes by seeking fundamental changes in the way economic benefits and costs of mining are distributed. Globally, they have attempted to win greater recognition of indigenous rights in international forums, pressurised national governments and global agencies to usher in changes in legislation by taking up litigation and directing political action, and mobilising new, voluntary (as well as compulsory) rules to regulate mining. In talking about sustainability, India's National Mineral Policy of 2019 does not really consider these developments. Instead, it 
presents a 'business-friendly' face, aimed at making extractive developments more streamlined, hoping to invite foreign direct investments. This section is devoted to a number of concerns on the extractive landscape in India.

In providing a selective overview of the contents of this issue of EES, I underscore how, any analysis of research questions on ecology, economy and the society must involve values, rights and law as well as economic and social concerns. The journal is, slowly and steadily moving towards reflecting an understanding of working across disciplines. 